\title{
Effect of Superplasticizer Dosage on Compressive Strength and Microstructure of High Volume Basic-Oxygen Slag Mortar Exposed to Sea Water Attacks
}

\author{
Ahmed S. Ouda ${ }^{1,2}$ \\ 1. Housing and Building National Research Center, Dokki, Giza, Egypt \\ 2. The University College of Taymaa, University of Tabuk, Kingdom of Saudi Arabia \\ E-mail:aouda@ut.edu.sa
}

Received: 10 November 2020; Accepted: 3 December 2020; Available online: 10 January 2021

\begin{abstract}
The influence of superplasticizer addition on durability reinforcement of cement mortars made with basic-oxygen blast-furnace slag fine aggregate (BOF) as completely substitute for natural sand after being exposed to sea water solution for 6 months was evaluated by determining physico-mechanical characteristics in terms of water absorption and compressive strength in addition to microstructure analysis. In this procedure, all studied mixtures were doped with $1 \%$ and $2 \%$ superplasticizer. After the initial curing of samples in tap water for 28 days, they were subjected to sea water solution for 6 months using water to binder ratios of 0.35 and 0.45 . The new hydration phases and microstructure of hardened specimens were identified by X-ray diffraction (XRD) and scanning electron microscopy (SEM) techniques. The results showed that cement mortars with slag fine aggregate blended with $2 \%$ SP offered better water absorption, compressive strength and microstructure than their counterparts with natural sand against sea water attacks. Therefore, they can be used in offshore structure applications.
\end{abstract}

Keywords: Basic-oxygen blast-furnace slag; Cement mortar; Durability; Water absorption; Compressive strength; Scanning electron microscopy.

\section{Introduction}

The development of concrete structures exposed to offshore environment is one of the most prominent issues facing the concrete industries in the twenty-first century. The use of such industrial by-products having desirable characteristics in concrete can result in saving of energy as well it is limiting the consumption of natural resources [1]. The iron and steel industry over the world produce huge amounts of slag as by-products, including ground granulated blast furnace slag (GGBFS), basic-oxygen blast-furnace slag (BOF) and electric-arc-furnace slag (EAFS) [2]. Basic oxygen blast-furnace slag (BOF) is a final waste material in the basic oxygen furnace steel making process [3]. Some previous studies have been conducted to use BOF as fine aggregate substitute for sand. Of them, Yung-Chin et al. [4] prepared cement mortar using BOF slag as a fine aggregate. They concluded that the compressive and flexural strengths of specimens can reach 45.4 MPa and 7.1 MPa, respectively after different curing times. Bodor et al. [5] prepared cement mortar specimens using the BOF slag replaced with 50\% of natural sand aggregate. The mechanical and chemical properties of these mortars were enhanced at replacement level of $37.5 \%$, by weight. In the same vein, Monkman et al. [6] indicated that cement mortars made of the fine aggregate of carbonated BOF slag can achieve high 28-day strengths compared to those containing natural sand. On the other hand, Tung-Hsuan et al. [7] indicated that the use of BOF slag fine aggregate in cementitious mortars significantly reduced the compressive strength and slightly increased the volume expansion.

Recently, superplasticizer is considered one of the most important components of concrete mix. Concrete performance depends on the amount added and the extent to which it is distributed in the fresh mixture. Benaicha et al. [8] studied the correlation between the rheology and the compressive strength of self-compacting concrete. They concluded that increasing the superplasticizer dose leads to a decrease in compressive strength. Also, overdose decreases the $\mathrm{V}$-funnel flow time, yield stress and the plastic viscosity values. While, GolCaszewski and Szwabowski [9] investigated the influence of different superplasticizers on the rheology of the mortars using rotational viscometer. The results indicated that type and chemical composition of cement are important factors for the performance of SP. In addition, type and dosage of SP along with cement type show significant differences in rheological properties of mortar. Mohammed et al. [10] reported that overdose of SP (1200 ml/100 kg of OPC) had a negative effect on concrete properties by decreasing compressive strength and increasing porosity. Musbah 
et al. [11] studied the effect of three different dosages of SP (500, 750 and $1000 \mathrm{ml} / 100 \mathrm{~kg})$ on the properties of fresh and hardened concrete. The results showed that the optimum dosage of SP was $750 \mathrm{ml} / 100 \mathrm{~kg}$ of cement and concrete mixture with optimum dosage offered higher compressive strength values compared to reference mixtures without SP. On the other hand, Didouche et al. [12] studied the effect of three types of SP, namely polynaphthalenesulfonate (PNS), a melamine resin (PMS) and a polycarboxylate (PC) on rheological, mechanical and calorimeters properties of mortar made with limestone cement. The results showed that the PNS superplasticizer cause strength loss; while PMS superplasticizer at low content of $0.6 \%$ enhances strength although it is still less than the reference mortar. The addition of PC superplasticizer significantly increases compressive strength than control ones.

Durability is one of the most important characteristics to be considered in the design of reinforced concrete exposed to marine environment. Marangu et al. [13] pointed out that deterioration of concrete structures is generally caused by ingress of aggressive ions. Previous works indicated that various slags as by-products could replace natural sand in mortar and concrete structures against marine and aggressive environments. Santamaría et al. [14] reported satisfactory results in terms of physical and mechanical properties as well dimensional stability of concrete mixtures containing electric steelmaking aggregate (ESMA) after being exposed to aggressive environments compared to reference ones. Authors confirmed the suitability of slag-concrete for use in offshore structures. Whilst, Polanco et al. [15] prepared concrete structures using two types of steelmaking slags, namely electric-arc furnace slag (EAFS) and ladle-furnace slag (LFS). Specimens were evaluated for durability and resistance to external agents in terms of freezing-and-thawing cycles, wetting-and-drying cycles, potential expansion in hot water, and climatic chamber aging. They concluded that mixtures made with EAFS in form of coarse and fine aggregates offered excellent performance in aggressive media; however, the inclusion of LSF fines in EAFS mixtures negatively affected on the physico-mechanical properties of tested samples. Arribas et al. [16] studied the effect of chemical degradation such as sulphate attack, alkali-aggregate reaction and marine environment on concrete incorporating electric-arc furnace slag as a substitute for the conventional aggregate. The study emphasized the possibility of producing steel-reinforced concrete with slag aggregate. Humam and Siddique [17] studied the effects of replacement of sand- fine aggregate with high percentages of iron slag on compressive strength, split tensile strength, sulphate resistance and rapid chloride permeability test of cement mortar. The percentages of replacement were $0 \%, 10 \%, 20 \%, 30 \%$, and $40 \%$ by weight of fine aggregate. Results indicated that inclusion of iron slag as partial replacement with fine aggregate enhances the properties of Mortar. Other studies have included the use of blast-furnace as a partial substitute of cement for enhancing concrete resistance against aggressive environment. Of them, Najimi et al. [18] conducted a series of tests including compressive strength, expansion measurements and microstructural analysis on concrete made by replacing OPC with copper slag at levels of $0 \%, 5 \%, 10 \%$ and $15 \%$ against sulphate solution attack. The results indicated that the inclusion of slag had a significant effect on concrete properties.

Waste recycling of basic-oxygen blast-furnace slag from the iron and steel industry and reusing it in the production of low-cost cement mortar with unique properties will greatly contribute to the development of the construction industry and the preservation of natural resources from depletion. It is recognized that marine structures are designed to be exposed to the open sea environment. To deal with extreme conditions, it is necessary to design concrete structures with specific properties that meet the requirements of the surrounding environment. Concrete is an essential material that is widely used in the construction field as a result of its versatility, durability and economic properties. Mortar phases are assumed to be a major component of structural concrete. High compressive strength is achieved when the superplasticizer is added to the concrete mix design. Superplasticizer addition leads to a reduction of water to binder ratio as well as it reduces the cohesion of OPC particles by electrostatic repulsion. Moreover, the workability of fresh mixture requires the addition of an appropriate dose of superplasticizer. After extensive review by the author in the electronic library, it was noted that there is no research paper that examines the behavior of cement mortar containing BOF slag blended with various proportions of superplasticizer as a substitute for sand under the effect of sea water attacks. Therefore, the main objective of the current study is to evaluate the behavior of cement mortar containing BOF slag with/without SP before and after exposure to sea water solution for 1, 3 and 6 months. Treated mixtures were compared with their counterparts containing sand with/without SP at similar curing ages. In this procedure, some mixtures were designed by completely replacing of sand with BOF slag aggregate. To enhance sustainability against aggressive environment, all mixtures were doped with $1 \%$ and $2 \%$ superplasticizer. Water absorption and compressive strength before and after exposure were determined at zero time (28 days), 1, 3 and 6 months. The new phases and microscopic analysis of hardened samples were identified using XRD and SEM techniques.

\section{Experimental details}

\subsection{Materials and mix proportioning}


The following section deals with the physico-mechanical properties of raw materials involved in the preparation of mortars. In the present paper, materials used include ordinary Portland cement- CEM I (42.5 N), in accordance with the requirements of ASTM C-150 [19], supplied by Suez Cement Plant. Two types of fine aggregates were used in the design of mixtures. The first was natural sand (S) with fineness modulus of 2.65 which was used in preparation of reference samples, while the other was basic-oxygen-blast-furnace slag aggregate (BOF), characterized by cubical shape and rough surface texture, provided from the Iron and Steel Plant, Helwan, Egypt. Fig. 1 shows particle size analysis of sand. In the design of some mixtures, BOF slag was completely substituted by sand. Before mixing procedure, materials were carefully washed to get rid of the adhesive fine particles, and then oven dried at $100{ }^{\circ} \mathrm{C}$ for $24 \mathrm{~h}$. Also, the BOF slag aggregate was passed through a $1 \mathrm{~mm}$ diameter sieve and retained on a $600 \mu \mathrm{m}$ sieve. The physical features of slag including roughness and hardness nature make it more durable than sand. Table 1 outlines the chemical composition of raw materials as conducted by XRF technique.

Table 1. Chemical composition of the raw materials, (wt., \%)

\begin{tabular}{cccc}
\hline Oxide content & OPC & S & BOF \\
\hline $\mathrm{SiO}_{2}$ & 21.26 & 94.84 & 8.70 \\
$\mathrm{Al}_{2} \mathrm{O}_{3}$ & 4.49 & 2.12 & 0.78 \\
$\mathrm{Fe}_{2} \mathrm{O}_{3}$ & 3.49 & 0.82 & 39.41 \\
$\mathrm{CaO}$ & 63.81 & 0.52 & 39.52 \\
$\mathrm{MgO}$ & 2.02 & 0.10 & 0.92 \\
$\mathrm{SO}_{3}$ & 3.11 & 0.11 & 0.24 \\
$\mathrm{~L} . \mathrm{O} . \mathrm{I}$ & 1.57 & 0.22 & 0.11 \\
$\mathrm{Na}_{2} \mathrm{O}$ & 0.14 & 0.27 & - \\
$\mathrm{K}_{2} \mathrm{O}$ & 0.09 & 0.69 & - \\
$\mathrm{Cl}$ & 0.03 & 0.06 & - \\
$\mathrm{Total}_{\mathrm{Ins}}^{-}$ & 99.97 & 99.98 & 89.68 \\
$\mathrm{Na}_{2} \mathrm{O} \mathrm{Eq}$ & 0.53 & - & - \\
$\mathrm{L} . \mathrm{S} . \mathrm{F}$ & 0.20 & - & - \\
$\mathrm{C}_{3} \mathrm{~A}$ & 0.92 & - & - \\
$\mathrm{C}_{3} \mathrm{~S}$ & 6.00 & - & - \\
$\mathrm{C}_{2} \mathrm{~S}$ & 54.15 & - & - \\
\hline
\end{tabular}

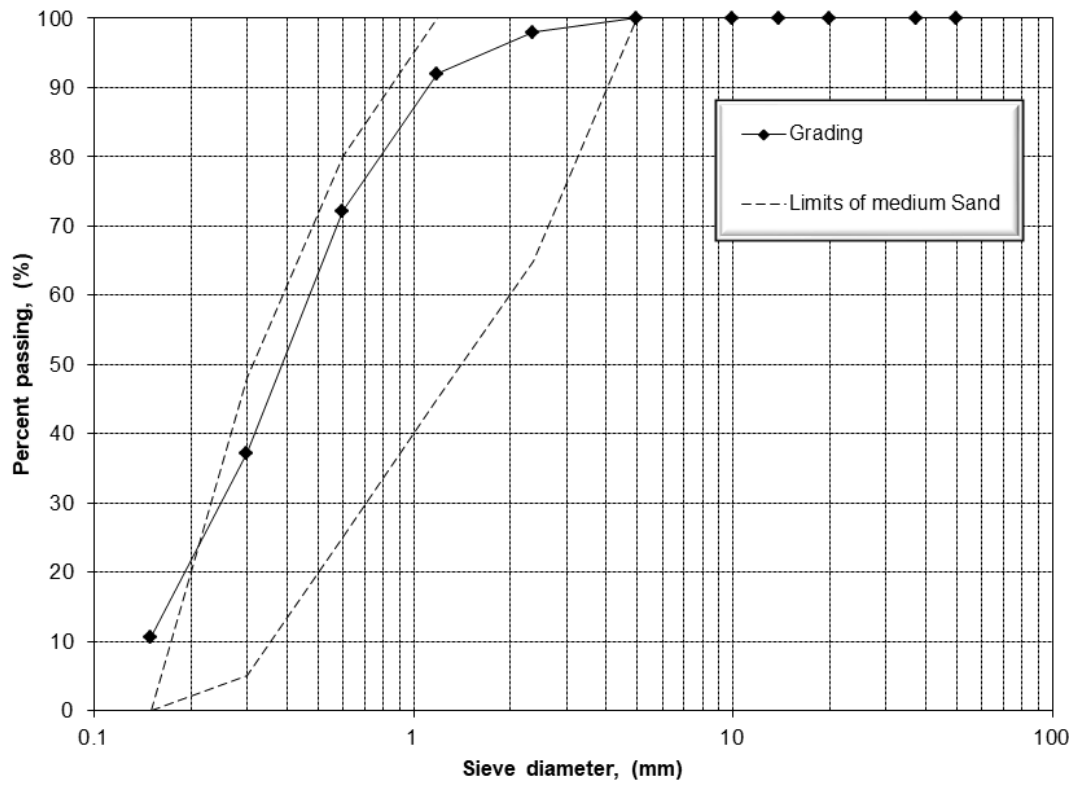

Fig. 1. Particle size distribution of sand

The quantified crystalline phases of BOF slag aggregate were investigated using XRD spectrum as given in Fig.2. Slag aggregate consists mostly of oxides which are similar to natural rocks and it also has alkaline properties such as OPC cement as indicated earlier by Kim et al. [20]. 


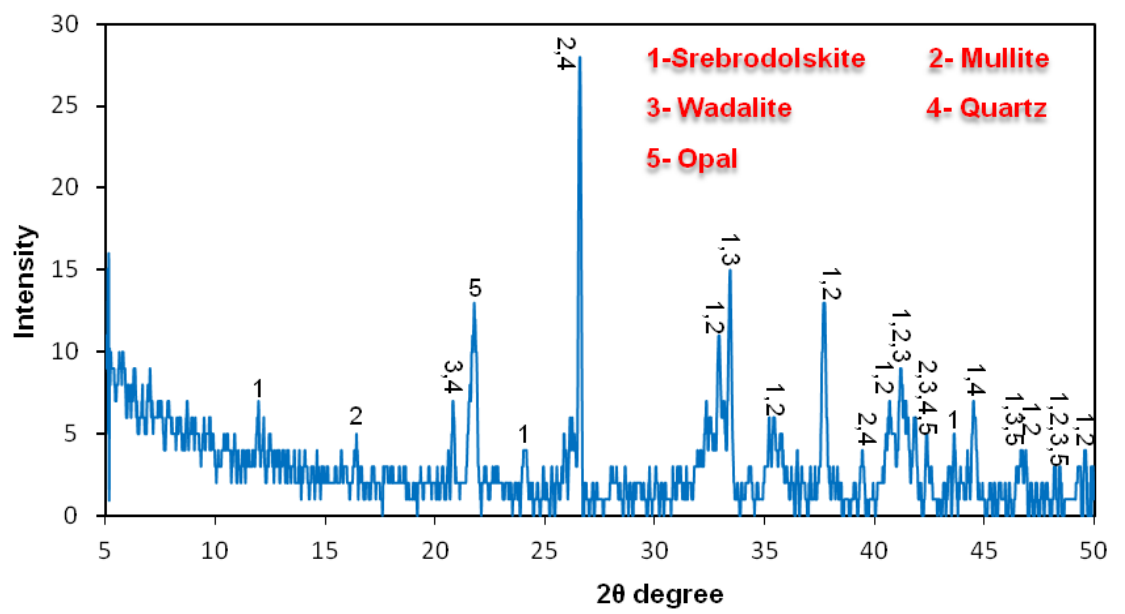

Fig. 2. XRD pattern of basic oxygen blast-furnace slag

The physical properties of BOF slag in comparison with natural sand were illustrated in Table 2. As it is cleared, BOF slag meets the requirements of ECCS 203 [21] and ESS 1109 [22] specifications. A Sikament-R 2004- based superplasticizer-type G (SP) with specific gravity of $1.195 \mathrm{~kg} / \mathrm{l}$ and solid content of $40 \%$, supplied from Sika Misr Company for Chemicals of Building Materials, Cairo, Egypt was used to promote sustainability of structures. Two classes of cement mortars with water/binder ratios of $0.35 \%$ and $0.45 \%$ were prepared. Reference superplasticized mortars blended with $1 \%$ and $2 \%$ SP of total weight of OPC was manufactured using sand as fine aggregate. Other superplasticized mixtures containg similar ratios of SP were made with BOF slag as fine aggregate.

The mixture proportions of all samples were summarized in Table 3. They had given labels S0, S1, S2, BOF0, BOF1 and BOF2 for sand and slag mortars, respectively.

Table 2. Physical properties of fine aggregates

\begin{tabular}{cccc}
\hline Properties & S & BOF & Acceptance and rejection limits \\
\hline Specific gravity & 2.52 & 2.9 & - \\
Water absorption (\%) & $<1$ & 1.6 & $\leq 2.5$ \\
Moisture content (\%) & 0.63 & 0.3 & according to ECCS 203 [21] \\
Bulk density (t/m $\mathrm{m}^{3}$ ) & 1.52 & 1.87 & - \\
Impact coefficient (\%) & - & 14 & $\leq 45$ \\
& & & according to ESS 1109 [22] \\
Crushing coefficient (\%) & - & 18 & according to ECCS 203 [21] \\
\hline
\end{tabular}

Table 3. Mixing proportions of all studied specimens (wt., \%)

\begin{tabular}{cccccc}
\hline \multirow{2}{*}{ Mixture ID } & \multicolumn{5}{c}{ Mix proportioning, (\%) } \\
\cline { 2 - 6 } & OPC & S & BOF & SP & w/b \\
\hline S0 & 25 & 75 & - & - & 0.45 \\
S1 & 25 & 75 & - & 1 & 0.35 \\
S2 & 25 & 75 & - & 2 & 0.35 \\
BOF0 & 25 & - & 75 & - & 0.45 \\
BOF1 & 25 & - & 75 & 1 & 0.35 \\
BOF2 & 25 & - & 75 & 2 & 0.35 \\
\hline
\end{tabular}

In dry conditions, the ratio of cement to fine aggregate has been determined to be 1:3 by weight for all mixtures. The raw materials were experimentally mixed together on dry using a bench-mounted mixer of 5 liter capacity to ensure complete homogeneity. After that the required amount of mixing water was poured. The superplasticizer and remaining of mixing water were added. Continuous and vigorous mixing was conducted for 5 min. The fresh pastes were cast in three layers into 25x25x25 mm cubic steel molds as recommended by El-Didamony et al. [23]. Subsequently, the pastes were manually pressed until each layer being consolidated using a vibrating table. After compacting top layer by hand, the outer surface of paste was smoothed by the aid of thin edged trowel. Subsequently, the specimens were covered with wet burlap, and then kept in laboratory at room temperature of $25^{\circ} \mathrm{C}$ for $24 \mathrm{hrs}$. After demoulding, specimens were cured in tap water for 28 days (zero-time). Thereafter, samples 
were submerged in sea water for 6 months. In order to keep the solution concentration as constant as possible, the solution is changed every month. The chemical composition of solution is presented in Table 4.

Table 4. The chemical composition of sea water solution

\begin{tabular}{ccccccccc}
\hline $\mathbf{p H}$ & $\mathbf{S O}_{3}$ & $\mathbf{C l}^{-}$ & $\mathbf{T D S}$ & $\mathbf{C a}^{2+}$ & $\mathbf{M g}^{2+}$ & $\mathbf{N a}^{+}$ & $\mathbf{K}^{+}$ & Total hardness \\
\hline 7.41 & 3601 & 21584 & 42650 & 311 & 1458 & 11993 & 480 & 6756 \\
\hline
\end{tabular}

The influence of sea water attacks on the physico-mechanical properties of hardened mixtures was investigated by determination of water absorption and compressive strength at different curing times. Once the compression test was performed on the selected samples, the hydration reaction was stopped by immersing crushed species in 1:1 methanol/acetone solution for $24 \mathrm{hrs}$. After that specimens were exposed to drying at $70^{\circ} \mathrm{C}$ for $1 \mathrm{~h}$, and then they kept in an air-tight bottle for further investigation. Water absorption test was conducted in accordance with ASTM C140 [24]. Absorption ratio was calculated using equation below:

$$
\text { Absorption, } \%=\left[\frac{\mathrm{W} 2-\mathrm{W} 1}{\mathrm{~W} 1}\right] \times 100
$$

where $\mathrm{W} 1$ is weight of sample after drying at $105^{\circ} \mathrm{C}$, W2 is the final weight of surface dry sample after immersion in water for $24 \mathrm{hrs}$.

\subsection{Testing procedure}

At specified immersion times, the compression test was measured in accordance with ASTM C109 M [25] by exposing three cubes of each mixture. The chemical composition of raw materials was performed using XRF Spectrometer Philips PW1400. The samples were prepared for analysis using (Rubidium) Rb-k $\alpha$ radiation tube at $50 \mathrm{kV}$ and $50 \mathrm{~mA}$. The XRD procedure was investigated using a Philips PW 1050/70 Diffractometer. The data were identified according to the XRD software (pdf-2: database on CD-Release 2005). The microstructure of hardened samples was studied using scanning electron microscope, SEM Inspect S (FEI Company, Holland).

\section{Results and discussion}

\subsection{Water absorption measurements}

To evaluate the pore characteristics, water absorption of the cement mortars has been determined. Fig. 3. described water absorption ratios of different mixtures blended with proportions of SP after being exposed to sea water for 1, 3 and 6 months. Reference samples manufactured using natural sand showed a decrease in water absorption values with increasing the exposure times up to $3 \mathrm{M}$, particularly S0, S1 and S2. Whilst similar mixtures made with BOF slag termed as BOF0, BOF1 and BOF2 exhibited a decrease of up to $6 \mathrm{M}$. This trend is attributed to the deposition of hydration products such as $\mathrm{C}-\mathrm{S}-\mathrm{H}$ in cementitious matrix, resulting in a compact and a dense microstructure, as it is proven by SEM (Fig. 7 c, d). The results indicated that the inclusion of SP to mix structure caused a decrease in water absorption depending on applicable ratio compared to plain mixtures. Superplasticized mortars with sand aggregate doped with 1\% SP displayed 16.24\%, 34.65\% and 36.81\% at 0, 1 and 3 months, respectively lower values than their counterparts free of SP. However, they offered a significant increase of 5.95\% at $6 \mathrm{M}$. Reduction trend of water absorption was achieved upon completely replacement of BOF slag with S. By comparing the reference samples for all mixtures, it was found that specimens with BOF aggregate experienced lower values of $0.13 \%, 3.84 \%, 0.66 \%$ and $4.57 \%$ at $0,1 \mathrm{M}, 3 \mathrm{M}$ and $6 \mathrm{M}$, respectively than those containing sand aggregate. Nadeem and Pofale [26] indicated that the reduction of water absorption could be attributed to good adhesion force between crystallized slag fine aggregate and cement paste as a result of rough surface of aggregate particles. The inclusion of SP ratio in mortar matrix with BOF slag had played a prominent role in water absorption reduction. Mixtures blended with 1\% exhibited 24.87\%, 27.93\%, 33.76\% and 38.28\%, respectively at all curing times compared to reference ones. However, they exhibited values of 25.78\%, 30.74\%, 36.67\% and 45.26\%, respectively upon increasing dosage to $2 \%$. Alsadey [27] pointed out that the decrease of water absorption for mixes blended with different ratios of SP is principally attributed the increase of entrapped water inside the cementitious matrix, which led to promotion of cement hydration.

\subsection{Compressive strength development}

The results of compressive strength of all mortars as a function of curing times up to 6 months are graphically represented in Fig. 4. As shown, compressive strength of mixes made with natural sand increased with increasing the testing time up to $3 \mathrm{M}$, and then decreased at $6 \mathrm{M}$. In contrast, mixes containing BOF slag as a fine aggregate exhibited a remarkable increase with age up to $6 \mathrm{M}$. Accordingly, mix S1 doped with 1\% SP showed a slight increase in an average of $1.33 \%$ at ages up to $3 \mathrm{M}$, followed by a decrease at later ages compared to the neat 
mixtures. With an increase of SP to 2\%, mix S2 indicated higher strength values in an average of $1.26 \%$ up to 1 $\mathrm{M}$, followed by a decrease of $0.6 \%$ at 3 and $6 \mathrm{M}$ than corresponding reference mortars. Sadrmomtazi et al. [28] indicated that higher SP dosage leads to the separation of the cementitious paste ingredients, which results in a reduction of viscosity and an increase of fluidity. As it would be expected, superplasticized reference specimens containing high volume BOF slag significantly increased compressive strength by $1.85 \%, 1.52 \%, 1.65 \%$ and $1.95 \%$, respectively at all different ages than those containing sand. Khanzadi and Behnood [29] attributed this tendency to the mechanical characteristics of slag aggregate. Moreover, the surface texture of aggregate is partly responsible for the increase of adhesion force between cement paste and aggregate in cementitious matrix due to the mechanical interlocking. By comparing the strength development of mixtures doped with ratios of SP at w/b of 0.35 ; it was observed that the mix BOF1 has achieved higher values of $1.65 \%, 1.42 \%, 1.74 \%$ and $2.90 \%$, respectively than corresponding mixes with sand at all ages. On the other hand, BOF slag mixtures with $2 \% \mathrm{SP}$ (BOF2) offered a gradual increase by $2.68 \%, 2 \%, 3.36 \%$ and $3.82 \%$ compared to their counterpart manufactured by sand.

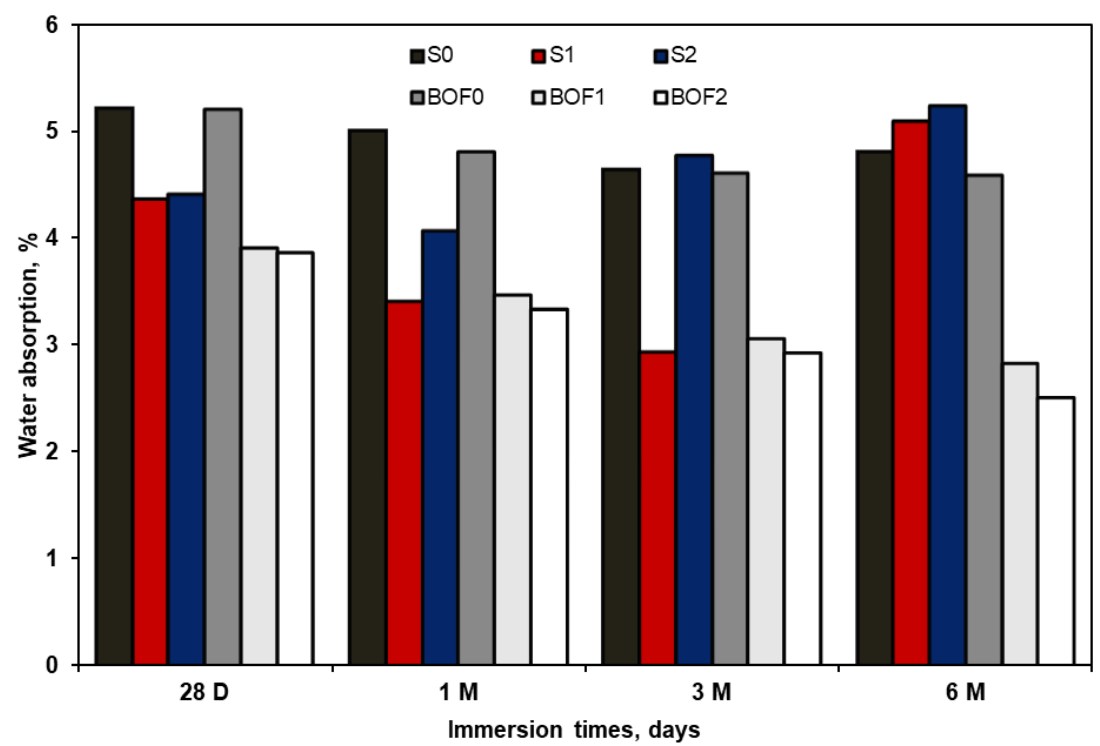

Fig. 3. Water absorption of cement mortars at different curing ages

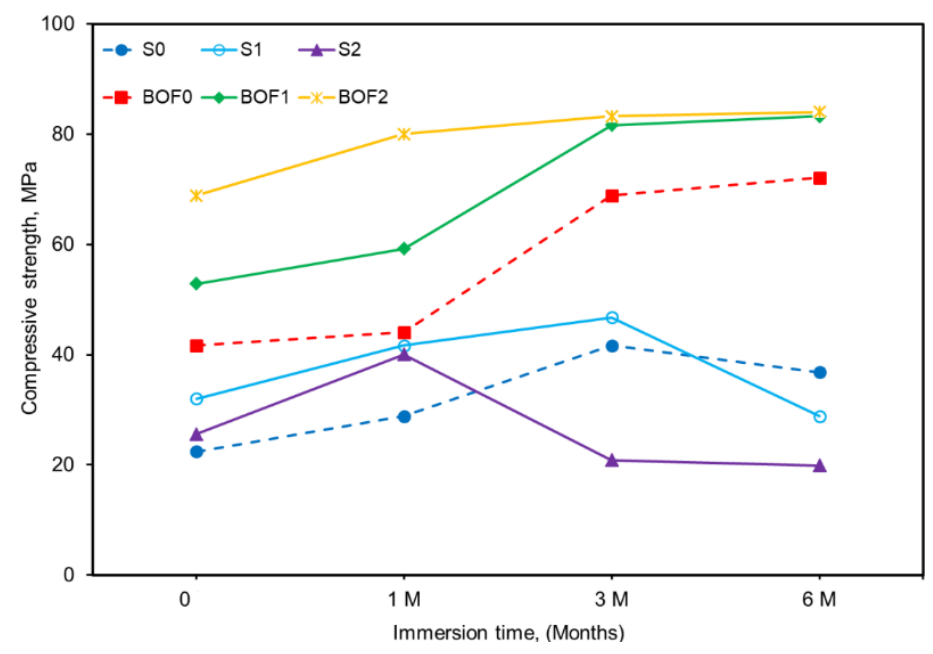

Fig. 4. Compressive strength of cement mortars at different immersion times

\subsection{Phase composition by XRD}

The results of X-ray diffraction analysis of cement mortars containing natural sand blended with $2 \%$ SP after being exposed to sea water solution for $6 \mathrm{M}$ are given in Fig. 5 . The samples were compared with their counterparts free of SP as well those hydrated in tap water for 28 days. The main hydration phases clearly identified in patterns were portlandite $\left[\mathrm{Ca}(\mathrm{OH})_{2}\right]$ as well un-hydrated larnite $\left(\beta-\mathrm{C}_{2} \mathrm{~S}\right)$. Obviously, dominant peaks of quartz, microcline 
and albite as constituents associated with sand aggregate were also detected. The area and intensity of portlandite peaks located at $2 \theta$ of 17.97 and 34.13 decreased with the progress of curing times. Although hydration occurs with liberation of $\mathrm{Ca}(\mathrm{OH})_{2}$, however, it is not inferred the existence of C-S-H phases in the patterns. This trend can be attributed to increase the intensity of quartz peaks or their appearance in amorphous structure. XRD pattern of cement mortar doped with $2 \%$ SP displayed similar phases as well similar behaviour as in case of control mixtures, suggesting that the inclusion of $2 \%$ SP does not alter the formed hydration products as explained earlier by Alsadey [27].

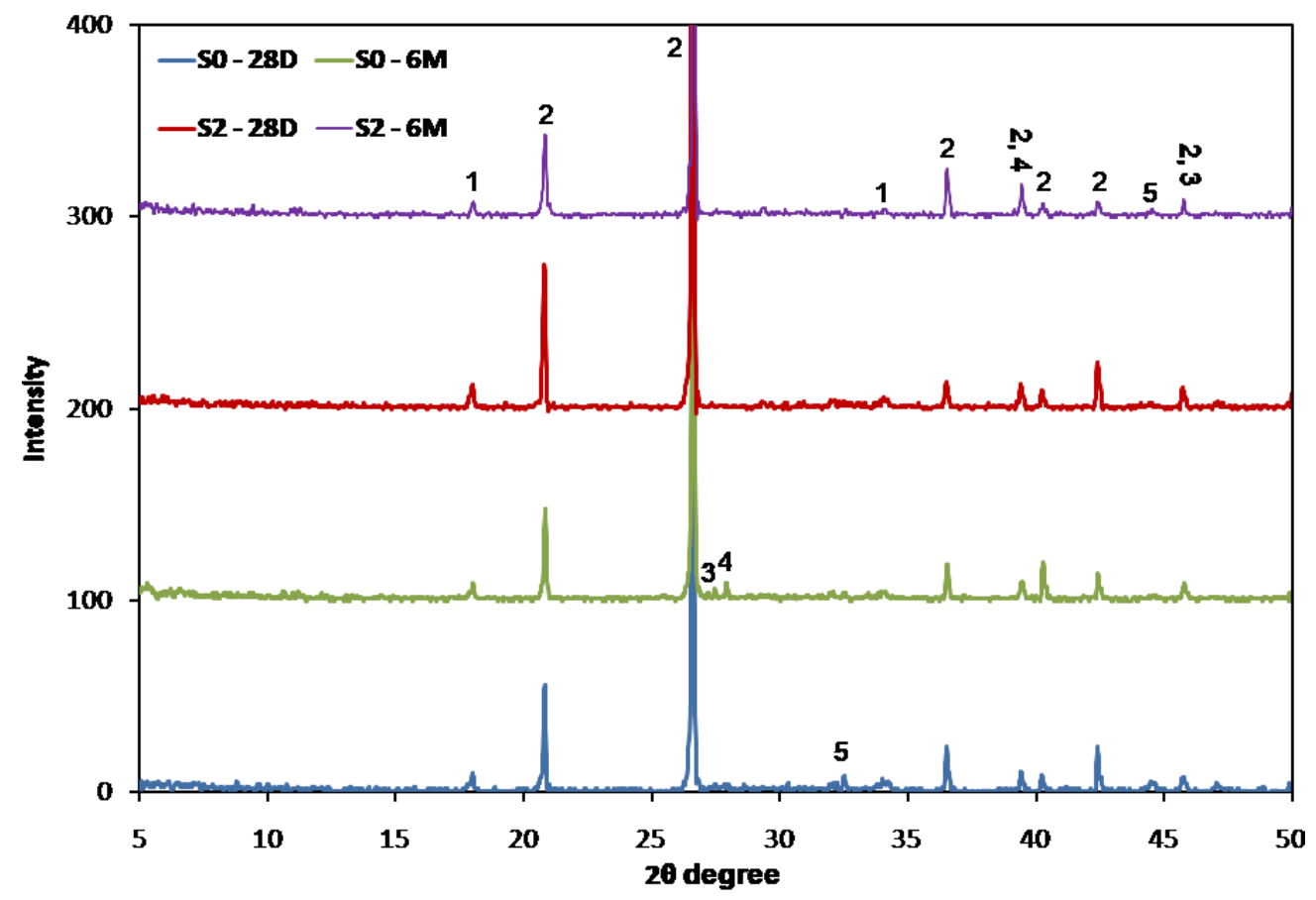

Fig. 5. XRD patterns of superplasticized cement mortars with sand aggregate cured for 28D and 6M (1: Portlandite, 2: Quartz, 3: Microcline, 4: Albite, 5: Belite)

On the other hand, Fig. 6 shows the XRD patterns of superplasticized slag-cement mortars with 2\% SP subjected to sea water solution for $6 \mathrm{M}$. After comparing them with plain mixtures, the patterns indicated the presence of $\mathrm{Ca}(\mathrm{OH})_{2}$, C-S-H and $\beta-\mathrm{C}_{2} \mathrm{~S}$ cement hydration phases with minor peak detected for $\mathrm{C}_{3} \mathrm{~S}$. In addition, crystalline phases of srebrodolskite, mullite, wadalite, quartz and opal were also appeared as main constituents of BOF slag aggregate. The results revealed that the area and intensity of peaks characterized for portlandite decrease as the age of curing increases. The reduction of $\mathrm{Ca}(\mathrm{OH})_{2}$ intensity and presence of $\mathrm{C}-\mathrm{S}$-H phases indicated that free lime was consumed with time forming C-S-H gel that is filled some of open pores. Likewise, the inclusion of SP increased the entrapped water and promoted hydration of cement, which resulted in a further enhancement of durability against seawater attacks. At all curing times, the peak distinguished for $\beta-C_{2} S$ is still present; pointing out the rate of hydration of $\mathrm{C}_{2} \mathrm{~S}$ is slower than $\mathrm{C}_{3} \mathrm{~S}$. Furthermore, crystalline phases characteristic for BOF slag aggregate are still detected for all samples, which contribute to good mechanical stability.

\subsection{Microscopic investigation by SEM}

The SEM micrographs of superplasticized cement mortars made with slag and natural aggregates blended with $2 \%$ SP cured for $6 \mathrm{M}$ are presented in Fig. 7, and then compared with their control mixtures at 28 days. Regarding reference mixture S2 as shown in Fig. 7a, the SEM photograph exhibited dense closely packed microstructure that consisted of crystal-like C-S-H phases distributed symmetrically throughout mortar matrix. Evidently, the inclusion of $2 \%$ SP developed a stronger interfacial transition zone (ITZ) between aggregate and cementitious paste. In the same context, the SEM micrographs of sample S2 hydrated for $6 \mathrm{M}$ (Fig. 7b), presented a relatively permeable microstructure by formation of microcracks spread over the microstructure, which resulted from the direct effect of sea water attacks. On the other hand, the SEM of superplasticized control slag mixture (BOF2) offered compacted and tough microstructure with lower porosity as well massive content of hydration products composed mainly of C-S-H from the hydration of OPC that filled most of the available pore spaces (Fig. 7c). Samples doped with 2\% SP (Fig. 7d) showed the densest microstructure which formed mainly of C-S-H. By comparison, we find that the obtained results fall in line with compressive strengths reported in Fig. 4. This 
enhancement related to the surface texture of slag aggregate responsible for increasing the adhesion force between binding material and aggregate particles in cementitious matrix, in addition SP accelerated hydration reaction by increasing the entrapped water.

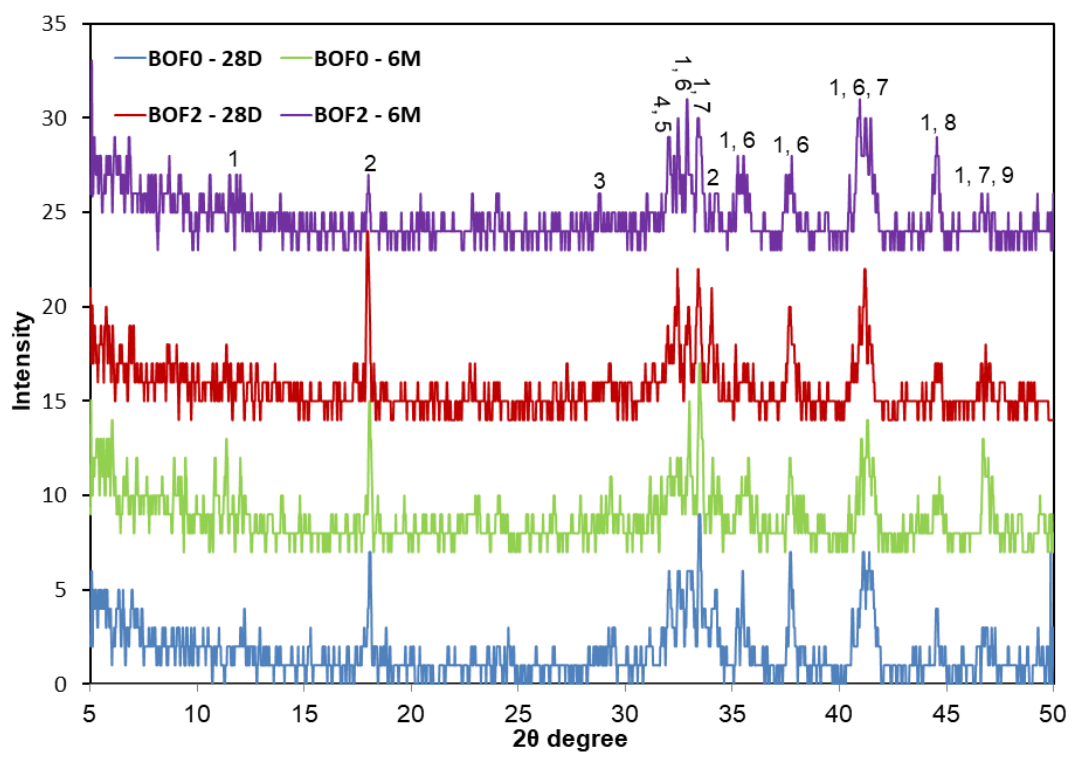

Fig. 6. XRD patterns of superplasticized cement mortars with slag aggregate cured for 28D and 6M (1: Srebrodolskite, 2: Portlandite, 3: Calcium silicate hydrate, 4: Belite, 5: Alite, 6: Mullite, 7: Wadalite, 8: Quartz, 9: Opal)
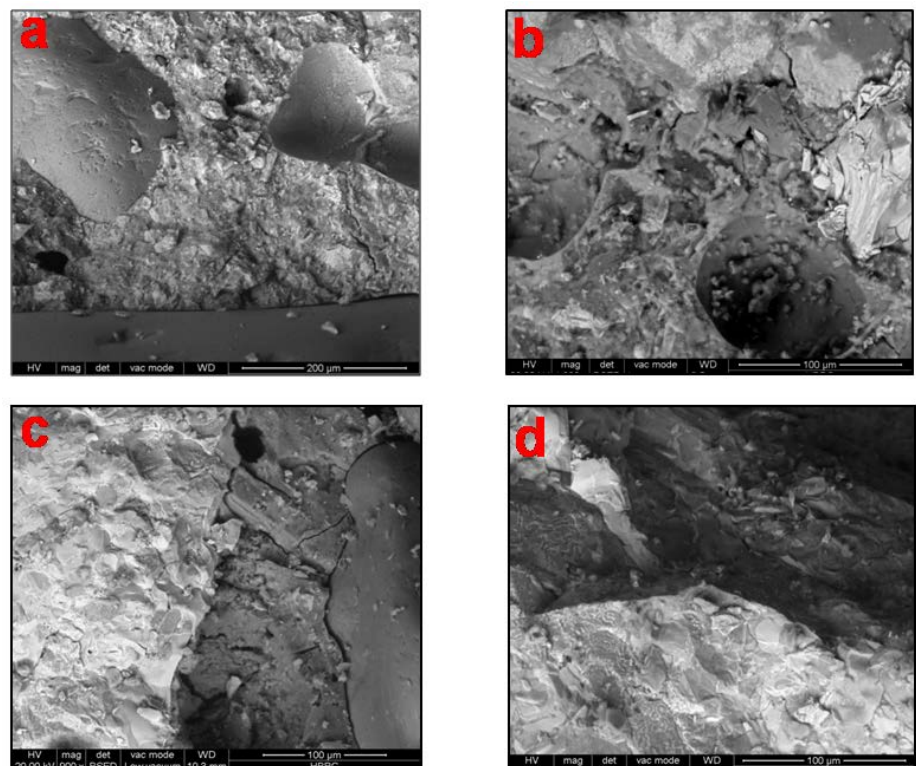

Fig. 7. SEM micrographs of superplasticized cement mortars containing sand and slag fine aggregates doped with 2\% SP (a: S2 - 28D, b: S2 - 6M, c: BOF2 - 28D, d: BOF2 - 6M)

\section{Conclusions}

This study presented the effect of superplasticizer addition on the physico-mechanical properties and microstructure of cement mortar incorporating basic-oxygen blast furnace slag fine aggregate as a full substitute for sand before and after exposure to sea water attacks at 1, 3 and 6 months. Water absorption, compressive strength and microscopic investigation of exposed and non-exposed samples were determined in normal and severe conditions. According to the obtained results, the following conclusions can be drawn:

1) Basic-oxygen blast furnace slag fine aggregate exhibited superior physical properties in terms of specific gravity, moisture content, bulk density and crushing coefficient than natural sand. 
2) Inclusion of $2 \%$ SP in cement mortar containing sand aggregate reduced water absorption for up to 3 months, followed by an increase at 6 months. Whereas samples containing BOF slag aggregate showed lower values at all immersion times.

3) In all cases, addition of SP and reduction of w/b ratio from 0.45 to 0.35 in cement mortar had a positive effect on the compressive strength of all mortars before and after exposure to sea water solution compared to reference mixes free of SP.

4) Samples incorporating BOF slag with $2 \%$ SP presented the highest compressive strength among all mixes at all curing ages. This behavior could be related to the surface texture of slag aggregate which responsible for increasing the adhesion force between the cementitious phases and aggregate particles. Moreover, addition of SP increases the entrapped water and then promotes the hydration reaction of OPC.

5) Regarding the SEM micrographs, cement mortar containing BOF slag with $2 \%$ SP showed a denser and more compact microstructure compared to samples containing sand.

6) Finally, cement mortar made with BOF slag fine aggregate can be used as an alternative to its counterpart containing sand in offshore structures.

\section{References}

[1] Alsadig DY, Wagialla KM. Effect of local steel slag on compressive strength of cement mortars. Journal of Advanced Chemical Engineering 2018; 8(2): 1-5.

[2] Yildirim IZ, Prezzi M. Chemical, mineralogical, and morphological properties of steel slag. Adv. Civ. Eng. 2011: 1-13.

[3] Motz H, Geiseler J. Products of steel slag an opportunity to save natural resource. Waste Manage. $2001 ; 21$ (3): 285-293.

[4] Yung-Chin D, Ta-Wui C, Ping-Chun L, Wei-Hao L. Study on the treatment of BOF slag to replace fine aggregate in concrete. Construction and Building Materials. 2017; 146: 644-651.

[5] Bodor M, Santos RM, Cristea G, Salman M, Cizer Ö, Iacobescu RI, Chiang YW, Balen KV, Vlad M, Gerven TV. Laboratory investigation of carbonated BOF slag used as partial replacement of natural aggregate in cement mortars. Cement and Concrete Composites. 2016; 65: 55-66.

[6] Monkman S, Shao Y, Shi C. Carbonated ladle slag fines for carbon uptake and sand substitute. J. Mater. Civ. Eng. 2009; 21 (11): 657-665.

[7] Tung-Hsuan L, Ying-Liang C, Pai-Haung S, Juu-En C. Use of basic oxygen furnace slag fines in the production of cementitious mortars and the effects on mortar expansion. Construction and Building Materials. 2018; 167: 768-774.

[8] Benaicha M, Hafidi Alaoui A, Jalbaud O, Burtschell Y. Dosage effect of superplasticizer on self-compacting concrete: correlation between rheology and strength. Journal of Materials Research and Technology.2019;8(2):2063-2069.

[9] GolCaszewski J, Szwabowski J. Influence of superplasticizers on rheological behaviour of fresh cement mortars. Cement and Concrete Research. 2004; 34: 235-248.

[10] Mohammed MS, Mohamed SA, Johari MAM. Influence of superplasticizer compatibility on the setting time, strength and stiffening characteristics of concrete. Advances in Applied Sciences. 2016; 1(2): 30-36.

[11] Musbah MG, Al Allam AM, Saleh HA, Ateeg IM. Effects of superplasticizing admixtures on the compressive strength of concrete. Universal Journal of Engineering Science. 2019; 7(2): 39-45.

[12] Didouche Z, Ezziane K, Kadri E. Predicted of hydration heat and compressive strength of limestone cement mortar with different type of superplasticizer. Advances in Concrete Construction. 2018; 6(6): 659-677.

[13] Marangu JM, Thiong'o JK, Wachira JM. Chloride ingress in chemically activated calcined clay-based cement. Journal of Chemistry. 2018: 1-8.

[14] Santamaría A, Orbe A, José JTS, González JJ. A study on the durability of structural concrete incorporating electric steelmaking slags. Construction and Building Materials. 2018; 161: 94-111.

[15] Polanco JA, Manso JM, Setién J, González JJ. Strength and durability of concrete made with electric steelmaking slag. ACI Materials Journal. 2011; 108(2): 196-204.

[16] Arribas I, Vegas I, San-José JT, Manso JM. Durability studies on steelmaking slag concretes. Materials and Design. 2014; 63: 168-176.

[17] Humam T, Siddique R. Properties of mortar incorporating iron slag. Leonardo Journal of Sciences. 2013; 23: 53-60.

[18] Najimi M, Sobhani J, Pourkhorshidi AR. Durability of copper slag contained concrete exposed to sulfate attack. Construction and Building Materials. 2011; 25(4): 1895-1905.

[19] ASTM C150. Standard specification for Portland cement; 2009.

[20] Kim KH, lim JY, Ryu DH, Choi SW. The present situation of production and its utilization of electronic arc furnace oxidizing slag in Korea and other countries. Magazine of Korea Concrete Institute. 2007; 19(6): 51- 
57.

[21] Egyptian Code of Practice for Reinforced Concrete (ECPRC) No. 203.2007.

[22] Egyptian Standard Specification No. 1109. Concrete aggregates from Natural Sources. 2002.

[23] El-Didamony H, Amer AA, El-Sokkary TM, Abd-El-Aziz H. Effect of substitution of granulated slag by aircooled slag on the properties of alkali activated slag. Ceramics International. 2013; 39: 171-181.

[24] ASTM C140. Standard test methods for sampling and testing concrete masonry units and related units. 2015.

[25] ASTM C109 M. Standard test method for compressive strength of hydraulic cement mortars. 2012.

[26] Nadeem M, Pofale AD. Replacement of natural fine aggregate with granular slag-A waste industrial byproduct in cement mortar applications as an alternative construction materials. International Journal of Engineering Research and Applications. 2012; 2(5): 1258-1264.

[27] Alsadey S. Effect of superplasticizer on fresh and hardened properties of concrete. Journal of Agricultural Science and Engineering. 2015; 1(2): 70-74.

[28] Sadrmomtazi A, Tajasosi S, Tahmouresi B. Effect of materials proportion on rheology and mechanical strength and microstructure of ultra-high performance concrete (UHPC). Construction and Building Materials. 2012; 187: 1103-1112.

[29] Khanzadi M, Behnood A. Mechanical properties of high-strength concrete incorporating copper slag as coarse aggregate. Construction and Building Materials. 2009; 23: 2183-2188.

(C) 2021 by the author(s). This work is licensed under a Creative Commons Attribution 4.0 International License (http://creativecommons.org/licenses/by/4.0/). Authors retain copyright of their work, with first publication rights granted to Tech Reviews Ltd. 